Research Paper:

\title{
Anxiety and Depression in Patients Undergoing Coronary crossuark Angioplasty
}

Leila Rouhi Balasi ${ }^{1}$, Arsalan Salari ${ }^{1}$, Azam Nourisaeed ${ }^{2 *}$, Fatemeh Moaddab ${ }^{3}$, Maryam Shakiba ${ }^{4}$, Hamed Givzadeh $^{5}$

1. Guilan Interventional Cardiovascular Research Center, Guilan University of Medical Sciences, Rasht, Iran

2. Department of Psychology, Faculty of Humanities, Rasht Branch, Islamic Azad University, Rasht, Iran.

3. Department of Nursing, Faculty of Nursing and Midwifery, Rasht Branch, Islamic Azad University, Rasht, Iran.

4. Department of Epidemiology, School of Health, Guilan University of Medical Sciences, Rasht, Iran.

5. Department of Cardiology, School of Medicine, Guilan University of Medical Sciences, Rasht, Iran.

Crtation: Rouhi Balasi, L., Salari, A., Nourisaeed, A., Moaddab, F., Shakiba, M., \& Givzadeh, H., 2016. Anxiety and Depression in Patients Undergoing Coronary Angioplasty. Journal of Client-Centered Nursing Care, 2(4), pp. 231-238. https://doi.org/10.32598/jccnc.2.4.231

dof: ${ }^{\text {: }}$ https://doi.org/10.32598/jccnc.2.4.231

Article info:

Received: 18 May 2016

Accepted: 10 Aug. 2016
Keywords:

Anxiety, Depression, Angioplasty, Coronary artery disease

\begin{abstract}
A B S T RA C T
Background: Anxiety and depression are the most important factors on the quality of life in patients after coronary angioplasty. These patients have less capability for adjusting themselves with changes in life style, diet, medication and physical activity adherence. This study aimed to determine predictive factors of anxiety and depression in patients undergoing coronary angioplasty.
\end{abstract}

Methods: In this descriptive cross-sectional study, 148 patients were selected by convenience sampling method. Data were collected by a 2 -section questionnaire, including sociodemographic factors and the hospital anxiety and depression scale. Multivariate logistic regression was used to determine predictors of anxiety and depression. Using a convenience sampling method, the patients were selected among those patients undergoing PCI in Heshmat Heart Medical Hospital in Rasht, Iran between March 2015 and June 2015. Analyses were performed using SPSS 19.

Results: The majority of samples were male (61.5\%), married (93.2\%), retired (31.1\%), and illiterate $(48 \%)$. Their Mean $( \pm \mathrm{SD})$ age was $60.02(10.5)$ years. According to the findings, $62.2 \%$ suffered from clinical anxiety and $20.3 \%$ suffered from clinical depression. The results of multivariate adjusted model showed that education level is significantly associated with mild depression. Also sex and age are significant predictors for severe depression. Male patients were less likely to have severe depression compared to female ones . Middle age patients (45-64 years) compared to older adults were more likely to be diagnosed with severe depression.

Conclusion: Considering the high prevalence of anxiety and depression symptoms in these patients, they need counseling, social and psychological support before, during and after procedures such as angioplasty.

\section{* Corresponding Author:}




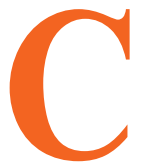

\section{Background}

ardiovascular diseases are the most common and persistent diseases which are life-threatening (Holt et al. 2013; Zhang 2015). They are the most cause of death all around the world (Baumeister et al., 2015; Furuya et al. 2013). As estimated, death due to cardiovascular diseases will be increased from 16.7 million in 2002 to 23.3 million in 2030 (Furuya et al. 2013; Holt et al. 2013). Also it is estimated that prevalence of cardiovascular disease in Tehran City is about 20\%-25\% (Dalir et al., 2013). Different studies have also incriminated this disease for $20 \%-45 \%$ death in Iran (Moattari et al., 2014). Different methods have been used for its treatment, such as medical therapy, Coronary Artery Bypass Grafting (CABG) or Percutaneous Coronary Intervention (PCI) (Aalto et al. 2006; Roohafza et al. 2015; Sharif et al. 2014). Coronary angioplasty is the most common method (Potluri et al. 2014; Sharif et al. 2014).

It is an aggressive procedure, typically to treat arterial atherosclerosis (Furuya et al. 2013). This method improves patient's prognosis and ability for exercising and walking as well as reduce ischemic events symptoms such as angina pectoris, dyspnea (Trotter, Gallagher \& Donoghue 2011). It is an effective and inexpensive therapeutic procedure with few side effects for revascularization (Park, Tahk \& Bae 2014; Son, Kim \& Park 2014).

Because of the invasive nature of the angioplasty, it is a stressful situation in the patients' live (Dalir et al. 2013). Many patients who underwent this procedure would face some kinds of mental problems (Chaudhury \& Srivastava, 2013; Dalir et al. 2013). Anxiety and depression are common among these patients (Chaudhury \& Srivastava, 2013; Ebadi et al. 2011; Roohafza et al. 2015; Wang et al. 2013). This can be due to short period of hospitalization and lack of mental support systems for patients (Sharif et al. 2014). However, health care providers think that coronary angioplasty is less invasive than surgery and patients experience less anxiety and depression and as a result, they think that their patients need less intervention and training (Ebadi et al. 2011).

Anxiety and depression among patients can be related to the progression of symptoms and coronary artery disease, weak performance status, recurrent cardiac events such as Myocardial Infarction (MI) and death (Bauer et al. 2012; Celano et al. 2015; Furuya et al. 2013; Gallagher et al. 2012; Moryś et al. 2015; Ozturk et al. 2015; van Dijk et al. 2015).

Anxiety and depression are the most important factors on the quality of life (Rafael et al. 2014) and may also affect physical aspects of quality of life such as left ventricular ejection fraction, pectoris angina and other chronic diseases (Ebadi et al. 2011). Anxiety and depression delay the adaptation period with the disease and have negative effects on patients' quality of life. Therefore, these patients have less capability for adjusting themselves with changes in life style, diet, medication and physical activity adherence (Sharif et al. 2014).

Now, regarding the high prevalence of coronary angioplasty and importance of anxiety and depression on the treatment outcomes, this study aimed to determine predictive factors of anxiety and depression in patients undergoing coronary angioplasty.

\section{Materials \& Methods}

\section{Study design and participants}

This is a descriptive cross-sectional study to estimate the prevalence of anxiety and depression among patients undergoing Percutaneous Coronary Intervention (PCI) and their predictive factors. A total of 148 subjects were calculated to estimate $50 \%$ depression among PCI patients with a precision of 0.08 and the probability of type I error as 0.05 . Using a convenience sampling method, the patients were selected among those patients undergoing PCI in Heshmat Heart Medical Hospital in Rasht, Iran between March 2015 and June 2015. The inclusion criteria comprised lack of psychological diseases in patients according to their medical records and doing coronary angioplasty for the first time. Also the study was approved by Guilan University of Medical Sciences review committee (IR.GUMS. REC.1930596704) and data was collected after announcing the reserch purpose and obtaining consent from the participants through interview.

\section{Data collection}

The research tools included two sections; first section refers to individual and social factors and the second section refers to hospital anxiety and depression. Individual and social variables, including age, gender, marital status, education level, history of any underlying disease, monthly income and residential location were asked from participants at least 6 months after surgery and data were collected by interviews and after obtaining written consent from the samples.

For determining anxiety and depression, we used Hospital Anxiety and Depression Scale (HADS) designed by Sigmund and Smith (1983) that was used for measuring anxiety and depression level in outpatients (Dalir et al., 
2013; Kaur et al. 2015). This questionnaire comprises two subscales and 7 items were used for measuring depression and 7 items were used for measuring anxiety. Each questionaire item was ranked sympotms intensity based on 4-point Likert-type from 0 (non) to 4 (intense). The maximum score for each subsacle is 21 and for the whole scale is 42 which can be a reflection of emotional disorder; the scores of each subscale range from 0 (no symptoms) to 21 (maximum of symptoms). Also the tool can be interpreted through classification; 0-7 indicates no clinical signs, 8-10 indicates weak mild depression or weak anxiety, 11-21 indicates clinical depression or clinical anxiety for both subscale (Dempe et al. 2013). The questionnaire was validated by Kaviani et al. and the results indicate that HADS has enough validity for applying in Iranian clinical population (Kaviani et al. 2009). Also in a pilot study, 15 questionnaire were filled by patients and then the $\alpha$ value for this population was estimated as 0.78 .

\section{Statistical analyses}

Data are presented as frequency (percentage) and Mean $( \pm \mathrm{SD})$ as appropriate. Chi-square test was used to evaluate the differences in distribution of sociodemographic variables between groups. All variables with $\mathrm{P}$ value less than 0.05 entered in multivariate adjusted model. To estimate Odds Ratios (ORs) and 95\% Confidence Intervals (CIs) of predictors for mild and severe levels of depression and anxiety compared to no clinical sign, multivariate multiple logistic regression models were used. Analyses were performed using SPSS 19.

\section{Results}

In this study, during sampling (between March 2015 and June 2015) all patients with inclusion criteria were entered in the study. Demographic characteristics are pre-

Table 1. Demographic characteristics of patients undergoing coronary angioplasty $(n=148)$

\begin{tabular}{|c|c|c|c|}
\hline \multicolumn{2}{|c|}{ Variables } & \multirow{2}{*}{$\begin{array}{c}\text { No. } \\
11\end{array}$} & \multirow{2}{*}{$\begin{array}{c}\text { \% } \\
7.4\end{array}$} \\
\hline \multirow{4}{*}{ Age, $y$} & $<44$ & & \\
\hline & $45-64$ & 84 & 56.8 \\
\hline & $>65$ & 53 & 35.8 \\
\hline & Mean \pm SD & & \\
\hline \multirow{2}{*}{ Gender } & Male & 90 & 60.8 \\
\hline & Female & 58 & 39.2 \\
\hline \multirow{3}{*}{ Marital status } & Single & 8 & 5.4 \\
\hline & Married & 138 & 93.2 \\
\hline & Widow & 2 & 1.4 \\
\hline \multirow{2}{*}{ History of disease } & Yes & 72 & 48.6 \\
\hline & No & 76 & 51.4 \\
\hline \multirow{4}{*}{ Education level } & Illiterate & 72 & 48.6 \\
\hline & Under diploma & 45 & 30.4 \\
\hline & Diploma & 16 & 10.8 \\
\hline & College & 15 & 10.1 \\
\hline \multirow{3}{*}{ Income level, Rials } & $<5000000$ & 123 & 83.2 \\
\hline & $5000000-10000000$ & 11 & 7.2 \\
\hline & $>10000000$ & 14 & 9.6 \\
\hline \multirow{2}{*}{ Residential location } & Urban & 91 & 61.5 \\
\hline & Rural & 57 & 38.5 \\
\hline
\end{tabular}


Table 2. The distribution of anxiety and depression in patients undergoing coronary angioplasty $(\mathrm{n}=148)$

\begin{tabular}{ccccc}
\hline Variable & $\begin{array}{c}\text { Lack of Clinical Signs } \\
\text { No. (\%) }\end{array}$ & $\begin{array}{c}\text { Weak } \\
\text { No. (\%) }\end{array}$ & $\begin{array}{c}\text { Clinical Sings } \\
\text { No. (\%) }\end{array}$ & Mean \pm SD \\
\hline Anxiety level & $5(3.4)$ & $51(34.5)$ & $92(62.2)$ & $11.07 \pm 1.96$ \\
Depression level & $58(39.2)$ & $60(40.5)$ & $30(20.3)$ & $8.34 \pm 2.69$ \\
\hline
\end{tabular}

Client-Centered Nursing Care

sented in Table 1 . The Mean $( \pm \mathrm{SD})$ age of participants was $60.02(10.55)$ years and most of them were male $(61.5 \%)$, married $(93.2 \%)$, retired $(31.1 \%)$, illiterate $(48 \%)$, and without history of underlying disease $(51.4 \%)$. More than half of the participants had a monthly income less than 5 milion Rails (70.3\%), resident in city $(61.5 \%)$ and most of them lived with their spouses and children (57.4\%). Table 2 presents the clinical degree of anxiety and depression in these patients. A total of 92 subjects $(62.2 \%)$ suffered from clinical anxiety and 30 subjects had clinical depression.
According to Table 3, no significant relationship exists between sex, age, marital status, education level, occupation, history of underlying disease and income level, residential location (city or village) with anxiety among these patients. However, there was a significant relationship between sex $(\mathrm{P}=0.002)$ and education levels $(\mathrm{P}=0.049)$ with depression (Table 3).

According to the results of univariate analysis, those variables with a $P$ values less than 0.05 were selected and entered in the multivariate adjusted model. Table 4 presents the results of the multiple logistic regression model for de-

Table 3. Association between sociodemographic characteristics and depression and anxiety in patients undergoing coronary angioplasty, $(\mathrm{n}=148)$

\begin{tabular}{|c|c|c|c|c|c|c|c|c|c|}
\hline \multirow{3}{*}{\multicolumn{2}{|c|}{ Variables }} & \multicolumn{4}{|c|}{ Depression } & \multicolumn{4}{|c|}{ Anxiety } \\
\hline & & \multirow{2}{*}{$\begin{array}{c}\text { Lack of } \\
\text { Clinical } \\
\text { Signs }\end{array}$} & \multirow{2}{*}{$\begin{array}{c}\text { Weak } \\
\text { No. (\%) } \\
\end{array}$} & \multirow{2}{*}{$\begin{array}{l}\begin{array}{c}\text { Clinical } \\
\text { Sings }\end{array} \\
\text { No. (\%) }\end{array}$} & \multirow[t]{2}{*}{$\mathbf{P}$} & \multirow{2}{*}{$\begin{array}{c}\text { No } \\
\text { Clinical } \\
\text { Signs }\end{array}$} & \multirow{2}{*}{$\begin{array}{c}\text { Mild } \\
\text { No. (\%) }\end{array}$} & \multirow{2}{*}{$\begin{array}{l}\text { Severe } \\
\text { No. (\%) } \\
\end{array}$} & \multirow[t]{2}{*}{$\mathbf{P}$} \\
\hline & & & & & & & & & \\
\hline \multirow{3}{*}{ Age (year) $)^{a}$} & $<44$ & $5(45.5)$ & $4(36.4)$ & $2(18.2)$ & \multirow{3}{*}{0.053} & $0(0.0)$ & $6(54.5)$ & $5(45.5)$ & \multirow{3}{*}{0.217} \\
\hline & $45-64$ & $33(39.8)$ & $27(32.5)$ & $23(27.7)$ & & $2(2.4)$ & $24(28.6)$ & $58(69.0)$ & \\
\hline & $>65$ & $20(37.7)$ & $28(52.8)$ & $5(9.4)$ & & $3(5.7)$ & 21(39.6) & $29(54.7)$ & \\
\hline \multirow{2}{*}{$\operatorname{Sex}^{\mathrm{a}}$} & Male & $42(47.2)$ & $37(41.6)$ & $10(11.2)$ & \multirow{2}{*}{$0.002 *$} & $4(4.4)$ & $27(30.0)$ & $59(65.6)$ & \multirow{2}{*}{0.3} \\
\hline & Female & $16(27.6)$ & $22(37.9)$ & $20(34.5)$ & & $1(1.7)$ & $24(41.4)$ & $33(56.9)$ & \\
\hline \multirow{2}{*}{$\begin{array}{l}\text { Marital } \\
\text { status }^{a}\end{array}$} & Single & $2(10.0)$ & $4(50.0)$ & $4(40.0)$ & \multirow{2}{*}{0.132} & $0(0.0)$ & $7(70.0)$ & $3(30.0)$ & \multirow{2}{*}{0.12} \\
\hline & Married & $56(40.9)$ & $55(40.1)$ & $26(19.0)$ & & $5(3.6)$ & $44(31.9)$ & $89(64.5)$ & \\
\hline \multirow{4}{*}{$\begin{array}{l}\text { Educational } \\
\text { level }^{a}\end{array}$} & Illiterate & $20(27.8)$ & $35(48.6)$ & $17(23.6)$ & \multirow{4}{*}{$0.049 *$} & $2(2.8)$ & $28(38.9)$ & $42(58.3)$ & \multirow{4}{*}{0.679} \\
\hline & Under diploma & $19(42.2)$ & $18(40.0)$ & $8(17.8)$ & & $1(2.2)$ & $13(28.9)$ & $31(68.9)$ & \\
\hline & Diploma & $9(56.2)$ & $4(25.0)$ & $3(18.8)$ & & $1(6.2)$ & $6(37.5)$ & $9(56.2)$ & \\
\hline & College & 10(71.4) & $2(14.3)$ & $2(14.3)$ & & $1(6.7)$ & $4(26.7)$ & $10(66.7)$ & \\
\hline \multirow{2}{*}{$\begin{array}{l}\text { History of } \\
\text { disease }^{a}\end{array}$} & Yes & $26(36.1)$ & $34(47.2)$ & 12(16.7) & \multirow{2}{*}{0.207} & $3(4.2)$ & $24(33.3)$ & $45(62.5)$ & \multirow{2}{*}{0.855} \\
\hline & No & $32(43.7)$ & $25(33.3)$ & $18(24.0)$ & & $2(2.6)$ & $27(35.5)$ & $47(61.8)$ & \\
\hline \multirow{3}{*}{$\begin{array}{l}\text { Income level, } \\
\text { Rials }^{\mathrm{a}}\end{array}$} & $<5000000$ & $39(37.5)$ & $48(46.2)$ & $17(16.3)$ & \multirow{3}{*}{0.091} & $4(3.8)$ & $39(37.5)$ & $61(58.7)$ & \multirow{3}{*}{0.096} \\
\hline & $5000000-10000000$ & $7(77.8)$ & $2(22.2)$ & $0(0.0)$ & & $0(0.0)$ & $1(11.1)$ & $8(88.9)$ & \\
\hline & $>10000000$ & $7(63.6)$ & $4(36.4)$ & $0(0.0)$ & & $1(8.3)$ & $1(8.3)$ & $10(83.3)$ & \\
\hline \multirow{2}{*}{$\begin{array}{l}\text { Residential } \\
\text { location }^{\mathrm{a}}\end{array}$} & Urban & $40(44.4)$ & $33(36.7)$ & $17(18.9)$ & \multirow{2}{*}{0.293} & $2(2.2)$ & $30(33)$ & $59(64.8)$ & \multirow{2}{*}{0.505} \\
\hline & Rural & 18(31.6) & $26(45.6)$ & $13(22.8)$ & & $3(5.3)$ & $21(36.8)$ & $33(57.9)$ & \\
\hline
\end{tabular}

*: Significant results

Client-Centered Nursing Care

a: Chi-Square test 
Table 4. Multivariate adjusted model for depression in patients undergoing coronary angioplasty

\begin{tabular}{|c|c|c|c|c|c|c|c|c|c|}
\hline \multirow{2}{*}{\multicolumn{2}{|c|}{ Variables }} & \multicolumn{4}{|c|}{ Mild Depression } & \multicolumn{4}{|c|}{ Severe Depression } \\
\hline & & Beta & $\begin{array}{c}\text { Wald } \\
\text { Test }\end{array}$ & OR $(95 \% \mathrm{Cl})$ & $\mathbf{P}$ & Beta & $\begin{array}{c}\text { Wald } \\
\text { Test }\end{array}$ & OR $(95 \% \mathrm{Cl})$ & $\mathbf{P}$ \\
\hline \multirow{3}{*}{ Age } & $\leq 44$ & 0.30 & 0.14 & $1.35(0.27-6.77)$ & 0.71 & 1.34 & 1.53 & $3.83(0.45-32.14)$ & 0.22 \\
\hline & $45-64$ & -0.13 & 0.09 & $0.88(0.38-2.01)$ & 0.75 & 1.39 & 5.13 & 4.03(1.21-13.47) & $0.02 *$ \\
\hline & $\geq 65$ (referent) & 0.0 & - & 1.0 & - & 0.0 & - & - & - \\
\hline Sex & $\begin{array}{c}\text { Male } \\
\text { Female (referent) }\end{array}$ & $\begin{array}{c}-0.06 \\
0.0\end{array}$ & 0.02 & $\begin{array}{c}0.94(0.4-2.19) \\
1.0\end{array}$ & 0.89 & $\begin{array}{c}-1.44 \\
0.0\end{array}$ & 7.41 & $0.24(0.08-0.67)$ & $0.006 *$ \\
\hline \multirow{4}{*}{ Education } & Illiterate & 2.17 & 5.93 & $8.78(1.53-50.48)$ & $0.01 *$ & 1.35 & 2.10 & $3.87(0.62-24.15)$ & 0.15 \\
\hline & Under diploma & 1.57 & 3.29 & $4.81(0.88-26.1)$ & 0.07 & 0.75 & 0.66 & $2.12(0.35-12.93)$ & 0.42 \\
\hline & Diploma & 0.81 & 0.66 & $2.24(0.32-2.01)$ & 0.42 & 0.71 & 0.45 & $2.04(0.25-16.37)$ & 0.50 \\
\hline & College (referent) & 0.0 & - & 1.0 & - & 0.0 & - & 1.0 & - \\
\hline
\end{tabular}

No clinical sign serves as the referent group. OR: Odds Ratio, CI: Confidence Interval

*Significant results.

pression. Using no clinical sign of depression as the reference category, illiterate patients were more likely to have mild depression compared to patients with college education (illiterate: $\mathrm{OR}=8.78,95 \% \mathrm{CI}=1.53-50.48$ ). Sex and age were significant predictors of severe depression. Male patients were less likely to have severe depression compared to female ones $(\mathrm{OR}=0.24,95 \% \mathrm{CI}=0.08-0.67)$. Middle age patients (45-64 years) compared to older adults were more likely to be diagnosed with severe depression $(\mathrm{OR}=4.03,95 \% \mathrm{CI}=1.21-13.27)$.

\section{Discussion}

The present research indicates that most patients who underwent coronary angioplasty suffered from clinical anxiety so the therapeutic team should pay especial attention to these patients. A research was carried out to investigate the prevalence of anxiety and depression and treatment outcomes in patients with history of hospitalization in coronary care unit. The research indicated that $90 \%$ of patients suffered from anxiety (Beyraghi, Tonekaboni \& Vakili, 2006). Stress and anxiety delay the adaptation period, impose negative effects on patients' quality of life and postpone their return to social activities and occupation (Sharif et al. 2014).

Regarding depression subscale, clinical depression was reported only in $20.3 \%$ of cases. In a study of anxiety and depression among patients suffering from coronary artery disease, Moradian et al reported that $38 \%$ of participants suffered from mild to severe degree of depression (Moradian et al. 2013). However, this level of depression is also important as it has its own effects on treatment consequences. Evidence indicates that depression has a signifi- cant relationship with increased death rate and side effects of cardiovascular disease (Ebadi et al. 2011). Depression is also related to pathophysiological mechanisms of coronary artery disease such as unhealthy life style and lower medication adherence (Furuya et al. 2013).

In the current study, there was no significant association between sociodemographic variables and anxiety. Regarding the depression, the result of multivariate adjusted model indicated a significant relationship between education level and mild depression, i.e., illiterate participants had significantly higher level of mild depression compared to patients with a college education. Also Cunha et al. (2016)carried out a research with the purpose of studying the presence of depressive symptoms in patients with coronary artery disease and their results indicated that depression among patients with lower educational level was higher than the other people. Indeed low level of education can lead to a decrease in social activities and establishment of depression (Beyraghi, Tonekaboni \& Vakili, 2006).

In the present study, also the result of multivariate adjusted model indicated a significant relationship between sex and age with severe depression. According to this, female participants had higher level of depression than male participants and the results were in the same path as Furuya et al. who studied the association between sex and the presence of anxiety and depression after hospital discharge in patients who underwent Percutaneous Coronary Intervention (PCI). In their research, it was revealed that depression is more common among women than men (Furuya et al. 2013). Because women seem to be more sensitive and emotional than men and are also threatened by psychologi- 
cal problems and tensions in different life crises more than men (Paryad, Hosseinzadeh \& Kazemnejad Leili 2014).

Age was associated with severe depression in that the odds of severe depression in patients aged 45-64 years was significantly higher than older adults. In Pedersen et al. study, results showed that patients with depressive symptoms were generally older (age $>60$ years) (Pedersen et al. 2006). But in Wang et al. study, there was no significant correlation between age and depression score (Wang et al. 2012). The researcher believes that this finding may be due to the involvement of these groups in life problems. But older people have more peace of mind.

Because of the high prevalence of anxiety and depression among patients undergoing coronary angioplasty and its effects on disease process, adherence to treatment, quality of life and the like, it seems that psychological consultation is required before and after the procedure. Also it is recommended to pay attention to symptoms of depression and anxiety in order to handle and care these patients; because in many cases, these symptoms may be hidden and left undetected. Also future care plan of these patients to be set according to their predictors such as age and educational level. The limitation of this study was small sample size and convenience sampling method. So a study with a larger sample size is recommended.

\section{Acknowledgments}

The present research is a part of an approved proposal supported by Guilan University of Medical Sciences Research Department (Grant ID: 93100813). Therefore, I would like to express my gratitude to Guilan University of Medical Sciences Research Department, Guilan Interventional Cardiovascular Research Center, and Dr. Heshmat who was in charge of Medical Educational Center in Rasht City as well as patients who had assisted the researcher in carrying out the present research without whom it was not possible.

\section{Conflict of Interest}

The authors declared no conflict of interests.

\section{References}

Aalto, A. M., et al., 2006. Sociodemographic, disease status, and illness perceptions predictors of global self-ratings of health and quality of life among those with coronary heart disease: One year follow-up study. Quality of Life Research, 15(8), pp. 1307-22. doi: 10.1007/s11136-006-0010-3
Bauer, L. K., et al., 2012. Effects of depression and anxiety improvement on adherence to medication and health behaviors in recently hospitalized cardiac patients. The American Journal of Cardiology, 109(9), pp. 1266-71. doi: 10.1016/j.amjcard.2011.12.017

Baumeister, H., et al., 2015. Inpatient and outpatient costs in patients with coronary artery disease and mental disorders: A systematic review. BioPsychoSocial Medicine, 9(1). doi: 10.1186/ s13030-015-0039-z

Beyraghi, N., Tonekaboni, S. H., \& Vakili, G. H., 2006. [Anxiety and depression in patients admitted in cardiac care unit, TaleghaniHospital, Tehran, Iran, 2003 (Persian)]. Bimonthly Journal of Hormozgan University of Medical Sciences, 9(4), pp. 261-4.

Celano, C. M., et al., 2015. Association between anxiety and mortality in patients with coronary artery disease: A meta-analysis. American Heart Journal, 170(6), pp. 1105-15. doi: 10.1016/j. ahj.2015.09.013

Chaudhury, S., \& Srivastava, K., 2013. Relation of depression, anxiety, and quality of life with outcome after percutaneous transluminal coronary angioplasty. The Scientific World Journal, 2013, pp. 465979. doi: 10.1155/2013/465979

Cunha, D. M. M., et al., 2016. Depressive symptoms in patients with coronary artery disease. Investigación y Educación en Enfermería 34(2), pp. 323-28. doi: 10.17533/udea.iee.v34n2a12

Dalir, Z., Vahdat Feizabadi, E., Mazlom, S., \& Rajaee Khorasani, A., 2013. [The effect of short-term cardiac rehabilitation program on anxiety and depression in patients after coronary artery bypass surgery (Persian)]. Evidence Based Care, 3(3), pp. 33-42.

Dempe, C., et al., 2013. Association of anxious and depressive symptoms with medication nonadherence in patients with stable coronary artery disease. Journal of Psychosomatic Research, 74(2), pp. 122-7. doi: 10.1016/j.jpsychores.2012.12.003

Ebadi, A., Moradian, S. T., Feyzi, F., \& Asiabi, M., 2011. [Comparison of the hospital anxiety and depression among patients with coronary artery disease based on proposed treatment (Persian)]. Journal of Critical Care Nursing, 4(2), pp. 97-102.

Furuya, R. K., et al., 2013. [Anxiety and depression among men and women who underwent percutaneous coronary intervention (Portuguese)]. Revista da Escola de Enfermagem da USP, 47(6), pp. 1333-7. doi: 10.1590/s0080-623420130000600012

Gallagher, D., et al., 2012. Depression, anxiety and cardiovascular disease: Which symptoms are associated with increased risk in community dwelling older adults? Journal of Affective Disorders, 142(1-3), pp. 132-8. doi: 10.1016/j.jad.2012.04.012

Holt, R. I. G., et al., 2013. The relationship between depression, anxiety and cardiovascular disease: Findings from the Hertfordshire cohort study. Journal of Affective Disorders, 150(1), pp. 84-90. doi: 10.1016/j.jad.2013.02.026

Kaur, S., et al., 2015. Factor structure of hospital anxiety and depression scale in Malaysian patients with coronary artery disease. Asia Pacific Journal of Public Health, 27(4), pp. 450-60. doi: $10.1177 / 1010539514533719$

Kaviani, H., et al., 2009. [Reliability and validity of anxiety and depression hospital scales (HADS): Iranian patients with anxiety and depression disorders (Persian)]. Tehran University of Medical Sciences, 67(5), pp. 379-385.

Moattari, M., et al., 2014. Angina self-management plan and quality of life, anxiety and depression in post coronary angioplasty 
patients. Iranian Red Crescent Medical Journal, 16(11), p. 16981. doi: 10.5812/ircmj.16981

Moradian, S. T., Ebadi, A., Saeid, Y., \& Asiabi, M., 2013. [Hospital anxiety and depression in patients with coronary artery disease (Persian)]. Iranian Journal of Psychiatric Nursing, 1(2), pp. 54-61.

Moryś, J. M., et al., 2015. [The evaluation of stress coping styles and type $\mathrm{D}$ personality in patients with coronary artery disease (Polish)]. Kardiologia Polska, 73(7), pp. 557-66. doi: 10.5603/ kp.a2015.0039

Ozturk, S., et al., 2015. Anxiety and depression scores in patients with coronary artery disease and coronary artery ectasia. International Journal of Cardiology, 186, pp. 299-301. doi: 10.1016/j. ijcard.2015.03.305

Park, J. H., Tahk, S. J. \& Bae, S. H., 2015. Depression and anxiety as predictors of recurrent cardiac events 12 months after percutaneous coronary interventions. The Journal of Cardiovascular Nursing, 30(4), pp. 351-9. doi: 10.1097/jen.0000000000000143

Paryad, E., Hosseinzadeh, T., \& Kazemnejad Leili, E., 2014. [Predictors of anxiety and depression in patients undergoing coronary artery bypass surgery (Persian)]. Iranian Journal of Psychiatric Nursing, 2(2), pp. 67-80.

Pedersen, S. S., et al., 2006. Anxiety enhances the detrimental effect of depressive symptoms on health status following percutaneous coronary intervention. Journal of Psychosomatic Research, 61(6), pp. 783-9. doi: 10.1016/j.jpsychores.2006.06.009

Potluri, R., et al., 2014. The role of angioplasty in patients with acute coronary syndrome and previous coronary artery bypass grafting. International Journal of Cardiology, 176(3), pp. 760-3. doi: 10.1016/j.ijcard.2014.07.097

Rafael, B., et al., 2014. Vital exhaustion and anxiety are related to subjective quality of life in patients with acute myocardial infarct before cardiac rehabilitation. Journal of Clinical Nursing, 23(19-20), pp. 2864-73. doi: 10.1111/jocn.12563

Roohafza, H., et al., 2014. [Psychological state in patients undergoing coronary artery bypass grafting surgery or percutaneous coronary intervention and their spouses (Persian)]. International Journal of Nursing Practice, 21(2), pp. 214-20. doi: 10.1111/ijn.12234

Sharif, F., et al., 2014. The effects of discharge plan on stress, anxiety and depression in patients undergoing percutaneous transluminal coronary angioplasty: A randomized controlled trial. International Journal of Community Based Nursing and Midwifery, 2(2), pp. 60. PMCID: PMC4201194

Son, Y. J., Kim, S. H. \& Park, J. H., 2013. Role of depressive symptoms and self-efficacy of medication adherence in Korean patients after successful percutaneous coronary intervention. International Journal of Nursing Practice, 20(6), pp. 564-72. doi: 10.1111/ ijn.12203

Trotter, R., Gallagher, R. \& Donoghue, J., 2011. Anxiety in patients undergoing percutaneous coronary interventions. Heart $\mathcal{E}$ Lung: The Journal of Acute and Critical Care, 40(3), pp. 185-92. doi: 10.1016/j.hrtlng.2010.05.054

Van Dijk, M. R., et al., 2016. Depression and anxiety symptoms as predictors of mortality in PCI patients at 10 years of follow-up. European Journal of Preventive Cardiology, 23(5), pp. 552-8. doi $10.1177 / 2047487315571889$
Wang, Q., et al., 2012. The prevalence and predictors of anxiety and depression in adolescents with heart disease. The Journal of Pediatrics, 161(5), pp. 943-6.e1. doi: 10.1016/j.jpeds.2012.04.010

Wang, Z. J., et al., 2013. Association of depression with adverse cardiovascular events after percutaneous coronary intervention. Coronary Artery Disease, 24(7), pp. 589-95. doi: 10.1097/ mca.0b013e3283650234

Zhang, P., 2015. Study of anxiety/depression in patients with coronary heart disease after percutaneous coronary intervention. Cell Biochemistry and Biophysics, 72(2), pp. 503-7. doi: 10.1007/s12013014-0495-2 
Autumn 2016 . Volume 2. Number 4

Client-Centered Nursing Care

238 